\title{
Role of the Short Distance Order in Glass Reactivity
}

\author{
María Vallet-Regi ${ }^{1,2, *(1)}$ and Antonio J. Salinas $1,2, *$ (i) \\ 1 Departamento de Química en Ciencias Farmacéuticas, Universidad Complutense de Madrid, \\ Instituto de Investigación Sanitaria Hospital, 12 de Octubre imas12, 28040 Madrid, Spain \\ 2 Networking Research Center on Bioengineering, Biomaterials and Nanomedicine (CIBER-BBN), \\ 28040 Madrid, Spain \\ * Correspondence: vallet@ucm.es (M.V.-R.); salinas@ucm.es (A.J.S.); Tel.: +34-913-941-861 (M.V.-R. \& A.J.S.)
}

Received: 28 February 2018; Accepted: 8 March 2018; Published: 11 March 2018

\begin{abstract}
In 2005, our group described for the first time the structural characterization at the atomic scale of bioactive glasses and the influence of the glasses' nanostructure in their reactivity in simulated body fluids. In that study, two bioactive sol-gel glasses with composition $80 \% \mathrm{SiO}_{2}-20 \% \mathrm{CaO}$ and $80 \% \mathrm{SiO}_{2}-17 \% \mathrm{CaO}-3 \% \mathrm{P}_{2} \mathrm{O}_{5}$ (in mol- $\%$ ) were characterized by High-Resolution Transmission Electron Microscopy (HRTEM). Such characterization revealed unknown features of the glasses' structure at the local scale that allowed the understanding of their different in vitro behaviors as a consequence of the presence or absence of $\mathrm{P}_{2} \mathrm{O}_{5}$. Since then, the nanostructure of numerous bioactive glasses, including melt-prepared, sol-gel derived, and mesoporous glasses, was investigated by HRTEM, Nuclear Magnetic Resonance (NMR) spectroscopy, Molecular Dynamics (MD) simulations, and other experimental techniques. These studies have shown that although glasses are amorphous solids, a certain type of short distance order, which greatly influences the in vitro and in vivo reactivity, is always present. This paper reviews the most significant advances in the understanding of bioactive glasses that took place in the last years as a result of the growing knowledge of the glasses' nanostructure.
\end{abstract}

Keywords: bioactive glasses; nanostructure; short distance order; HRTEM; NMR spectroscopy

\section{Introduction}

Bioactive glasses (BGs) have been widely investigated in the last few decades for biomedical applications because they are biocompatible and bond to bone when implanted [1-7]. BGs can be classified as: Melt Prepared Glasses (MPGs), first reported in 1971 [8], Sol-Gel Glasses (S-GGs), in 1991 [9], and Mesoporous Bioactive Glasses (MBGs), in 2004 [10]. MPGs are dense materials, whereas S-GGs and MBGs are highly porous materials. Furthermore, MBGs exhibit surface area and volume of pores nearly double those of analogous S-GGs because they are synthesized in the presence of surfactants. Moreover, MBGs show mesopores arrangements in an extremely narrow pore size distribution.

In vitro assays in Simulated Body Fluid (SBF) [11-13] have played an important role in the design and evaluation of new BGs. The validity of these assays relies on the assumption that the apatite-forming ability of a biomaterial in SBF can be used as a predictor of a bioactive response when implanted. In 2014, Zadpoor reported that this assumption was valid in 25 of 33 studies of biomaterials reviewed [14]. In the majority of failure cases (i.e., 5/8), none of the biomaterials were able to form apatite in vitro, while they showed an in vivo bioactive behavior. However, for silica-based BGs, which this article addresses, the validity of this assumption is complete. Therefore, assays in SBF have also allowed the selection of the most promising BGs for evaluation in animal models. Moreover, these assays allowed the proposal of mechanisms of formation of the hydroxycarbonate 
apatite (HCA) layer, indicative of an in vitro bioactive response, as a consequence of variations in the glass composition or in the assay conditions.

Figure 1 shows the properties traditionally investigated as responsible for the bioactive response of each family of BGs. As is observed, for the dense MPGs, the in vitro bioactive response only depends on the glass composition. However, in S-GGs, the textural properties, i.e., surface area and porosity, must be also considered. Indeed, these properties produced a shift in the bioactivity window towards compositions richest in $\mathrm{SiO}_{2}$. Finally, the enhanced textural properties of MBGs accelerate their bioactive response.

Moreover, in vitro assays in SBF were the key to understanding the relationship between BG nanostructure and reactivity, first reported by our group in 2005 [15] and whose progress since then will be reviewed in this paper.

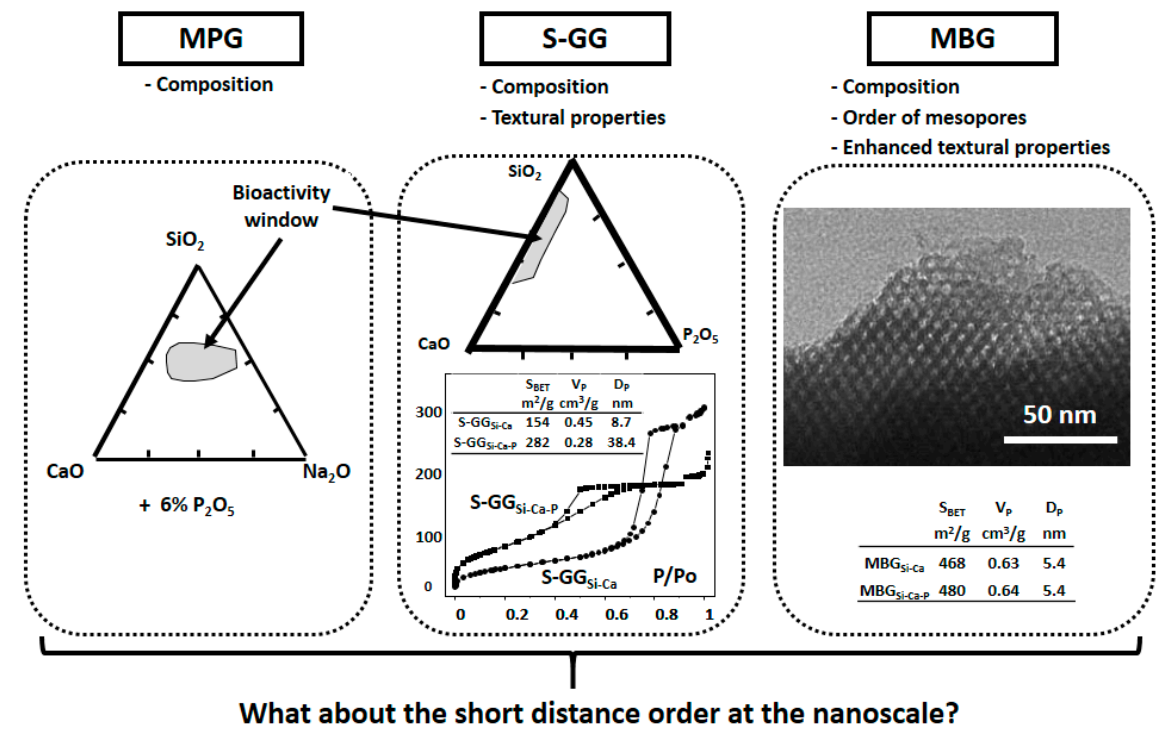

Figure 1. Properties which determine the bioactive response of the three families of BGs: MPGs, S-GGs, and MBGs. In the last decade, the importance of the nanostructure in this response for the three families of BGs has been also stressed.

\section{Traditional Characterization of Bioactive Glasses}

Traditionally, BGs were characterized before and after being soaked in SBF by X-Ray diffraction (XRD), Fourier Transform Infrared (FTIR) spectroscopy, Scanning Electron Microscopy (SEM), Energy Dispersive X-Ray (EDX) spectroscopy, Solid State Nuclear Magnetic Resonance (NMR) spectroscopy, X-ray Fluorescence (XRF), Transmission Electron Microscopy (TEM), electron diffraction (ED), X-ray Photoelectron Spectroscopy (XPS), and nitrogen adsorption. After a certain period soaked in SBF, the HCA formation on the glass surface indicative of a bioactive behavior is established when: (i) XRD and ED patterns can be assigned to an apatite-like phase, (ii) the FTIR spectrum contains two bands characteristic of phosphate in a crystalline environment (at 603 and $567 \mathrm{~cm}^{-1}$ ) and of carbonate groups (at 1440 and $875 \mathrm{~cm}^{-1}$ ) [16], and (iii) SEM and TEM show the typical needle-like shape particles of apatite, and EDX spectra indicates the new material formed is mainly composed of calcium and phosphorus. That way, the shorter the time of formation of HCA, the quicker the in vitro bioactive response of an investigated glass.

Figure 2 shows the assessment of the in vitro bioactive response of two S-GGs, the first one with composition $80 \% \mathrm{SiO}_{2}-20 \% \mathrm{CaO}\left(\mathrm{G}_{\mathrm{Si}-\mathrm{Ca}}\right)$, and the other one containing $3 \mathrm{~mol}-\%$ of $\mathrm{P}_{2} \mathrm{O}_{5}$ at the expense of the $\mathrm{CaO}\left(\mathrm{G}_{\mathrm{Si}-\mathrm{Ca}-\mathrm{P}}\right)$. SEM micrographs showed that after 7 days in SBF, the surfaces of both glasses were coated by a new material. The new bands observed by FTIR established that the new material contained $\mathrm{PO}_{4}{ }^{3-}$ groups in a crystalline environment, $\mathrm{CO}_{3}{ }^{2-}$ groups, and $\mathrm{H}_{2} \mathrm{O}$. In addition, 
EDX analysis showed that the new material was mainly composed of calcium and phosphorous. Finally, the ED patterns were indexed to a poorly crystallized apatite phase with somewhat bigger crystal size in $\mathrm{G}_{\mathrm{Si} \text {-Ca-P }}$ deduced by the presence of dots together with the rings [17]. All these results yield the conclusion that both glasses exhibited in vitro bioactivity because they were coated by HCA. However, the SEM images and the ED patterns indicated a bigger size of the HCA crystals formed on $\mathrm{G}_{\mathrm{Si}-\mathrm{Ca}-\mathrm{P} \text {. }}$
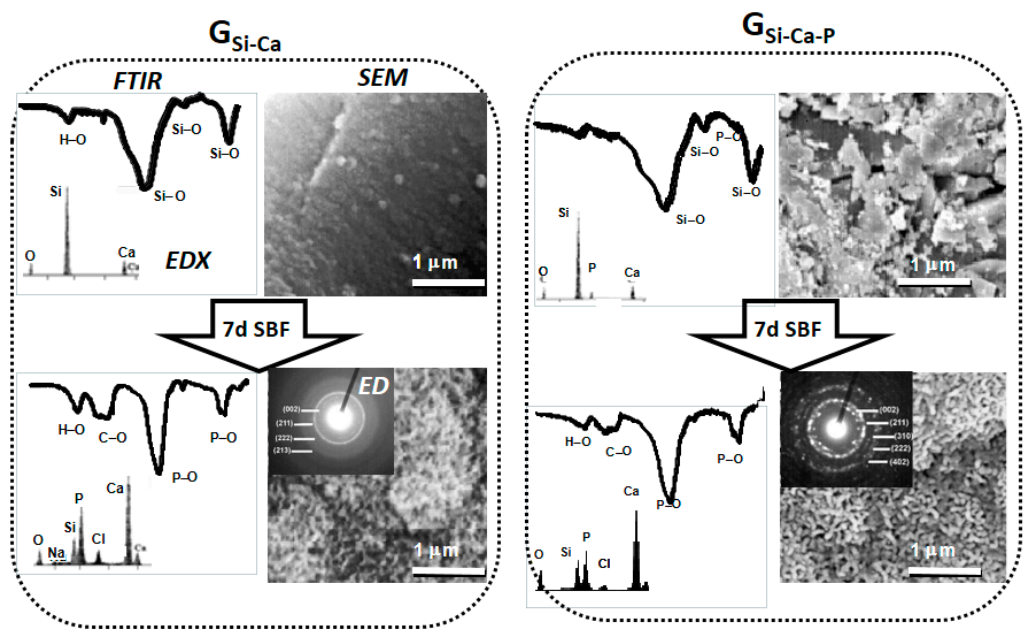

Figure 2. FTIR and EDX spectra, SEM images, and ED patterns of two bioactive glasses before and after being soaked for 7 days in SBF. Left: a P-free glass, $\mathrm{G}_{\mathbf{S i}-\mathrm{Ca}}$. Right: a glass with analogous composition but including 3 mol- $\%$ of $\mathrm{P}_{2} \mathrm{O}_{5}, \mathrm{G}_{\text {Si-Ca-P. }}$.

These results suggested that the inclusion of $\mathrm{P}_{2} \mathrm{O}_{5}$ in the glasses modified the HCA formation and pushed us to perform a study in three S-GGs containing $25 \mathrm{~mol}-\%$ of $\mathrm{CaO}$ and $0,2.5$ and $5 \%$ of $\mathrm{P}_{2} \mathrm{O}_{5}$, respectively (rest $\mathrm{SiO}_{2}$ ) [18]. Figure 3, top, shows the previous events that yielded the HCA crystallization: formation of a silica-rich layer and deposition of amorphous calcium phosphate (ACP) [2]. Figure 3, bottom, shows the times required to detect the formation of ACP and HCA for each glass.

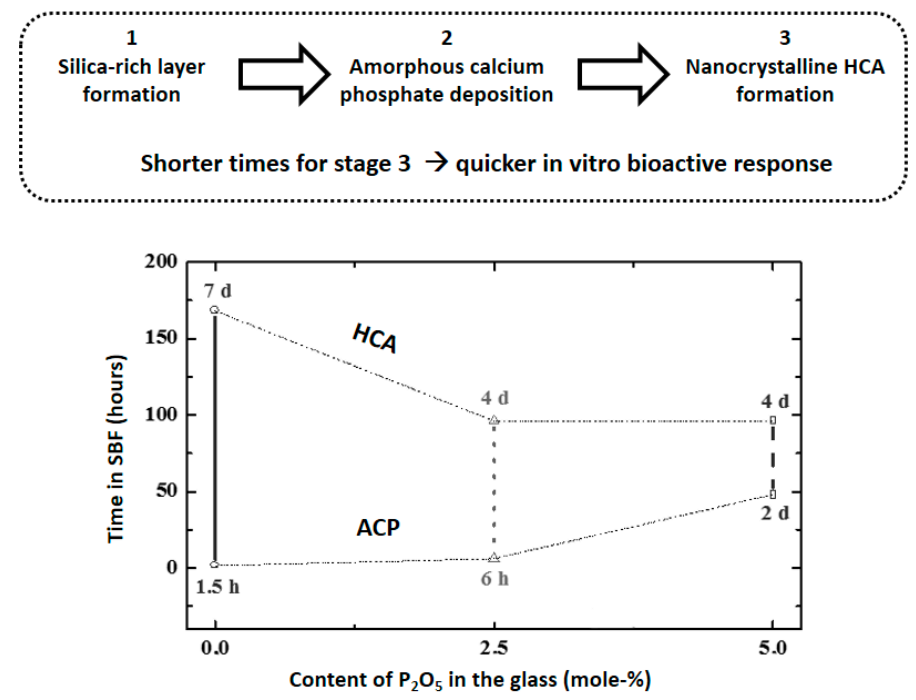

Figure 3. Top: Main outcomes after soaking a BG in SBF. Bottom: The times required for stages 2 and 3 for three silica-based sol-gel glasses containing, respectively, 0, 2.5 and 5.0 mol- $\% \mathrm{P}_{2} \mathrm{O}_{5}$. 
As is observed, the increase of $\mathrm{P}_{2} \mathrm{O}_{5}$ in the glasses decreases the required time for the HCA formation, that is, increases the bioactivity, although it retards the ACP formation. These results prompted us to propose different mechanisms for the HCA formation depending on whether or not the glass contained phosphorus. However, the traditional characterization methods did not allow the confirmation of these mechanisms. For this reason, we planned the nanostructural characterization of BGs with and without $P$ as is described in the following section.

\section{Nanostructure of Bioactive Glasses and Relationship with Their Bioactivity}

\subsection{Nanostructure of Bioactive Glasses from High-Resolution Transmission Electron Microscopy Analysis}

Two S-GG bioactive glasses, the first one P-free bioactive, $\mathrm{G}_{\mathrm{Si}-\mathrm{Ca}}$, and the second one including $3 \% \mathrm{P}_{2} \mathrm{O}_{5}, \mathrm{G}_{\text {Si-Ca-P, }}$, whose bioactivity was assessed in Figure 2, were characterized by High-Resolution Transmission Electron Microscopy (HRTEM) [15]. The high resolution image of $\mathrm{G}_{\text {Si-Ca }}$ in Figure 4a shows the typical contrast of an amorphous material but does not reveal any specific structural feature. However, this image can be filtered following the process: (i) digitizing the image, (ii) obtaining the Fourier transform (FT), (iii) filtering the FT by placing small windows around the fundamental spots, Figure $4 \mathrm{~b}$, and (iv) performing the inverse FT. The obtained noise-free image, Figure $4 c$, allowed us, for the first time, to reveal the structure at the atomic scale of a bioactive S-GG. The observed dots were correlated with positions of the tetrahedral units $\left[\mathrm{SiO}_{4}{ }^{4-}\right]$ and an average distance of $0.53 \mathrm{~nm}$ between the tetrahedra was determined for this P-free BG. The image shows local quasi-crystalline and crystalline blocks as well as some kind of chain connecting these different blocks. Figure $4 \mathrm{~d}$,e show the magnification of some regions of Figure 4c.

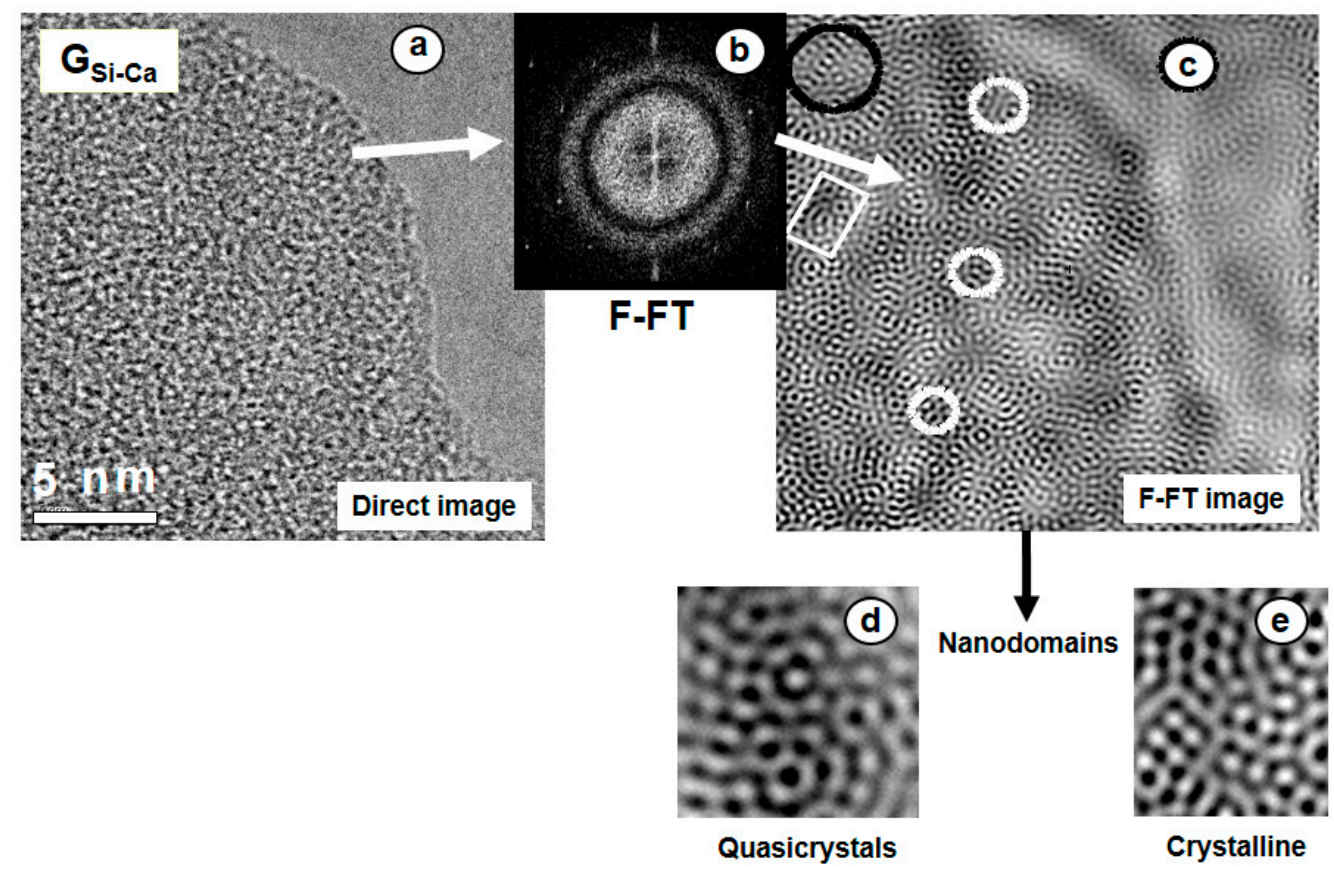

Figure 4. (a) Direct HRTEM image of $\mathrm{G}_{\mathrm{Si}-\mathrm{Ca}}$ glass where no specific structural feature is revealed. (b) The Filtered Fourier-Transform (F-FT) of the digitized image. (c) Noise-free reconstructed image shows the presence of crystalline and quasi-crystalline nanodomains more clearly noticeable in the magnified images $(\mathbf{d}, \mathbf{e})$.

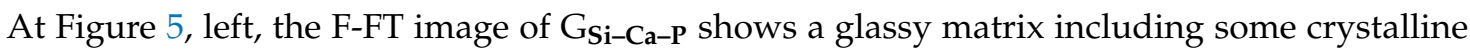
domains. The magnification of the amorphous part, Figure 5a, shows similar structural features as in $\mathrm{G}_{\mathrm{Si}-\mathrm{Ca}}$, but the average distance between $\left[\mathrm{SiO}_{4}{ }^{4-}\right.$ ] tetrahedra is now $0.36 \mathrm{~nm}$, that is, quite shorter than the $0.53 \mathrm{~nm}$ measured for the P-free glass. Moreover, Figure 5b,c show the magnified images of 
two crystalline areas with interplanar spacing close to $0.26 \mathrm{~nm}$. Figure 5 , right, superimposed with the image, shows now the EDX spectra of an amorphous region, Figure $5 d$, and of a crystalline region, Figure 5e. In addition, the magnified image of a crystalline area, Figure 5f, and its ED pattern, Figure 5g, are also included. EDX analyses revealed that phosphorus was only present in the crystalline regions and that amorphous areas were depleted in calcium. Particularly interesting is the ordered area at the bottom right, whose magnified image is depicted in Figure 5f, and its FT pattern in Figure $5 \mathrm{~g}$.

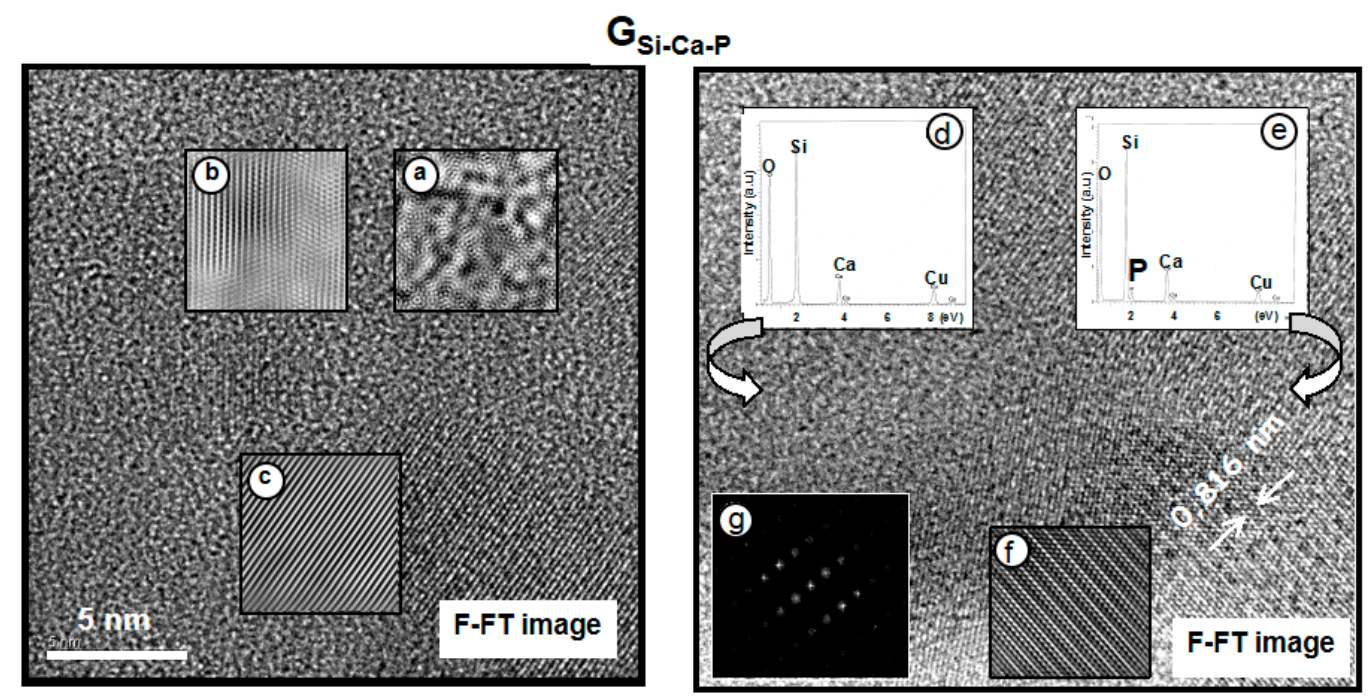

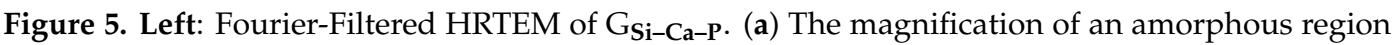
and of two crystalline areas (b,c). Right: (d) EDX spectra of an amorphous region, depleted in $\mathrm{P}$, and of a crystalline region (e), rich in P. (f) Magnification of the right lower corner of a crystalline region and its corresponding FT pattern $(\mathrm{g})$.

The FT diffraction pattern (Figure 5g) allowed the identification of the nanocrystalline phase. This pattern is characteristic of a material with rhombohedral symmetry like $\beta$-tricalcium phosphate $(\beta-\mathrm{TCP})$. However, the decrease of symmetry was explained by the inclusion of small amounts of silicon in the unit cell, seen in Figure 5e [19]. Thus, Figure $5 \mathrm{~g}$ was indexed on the basis of an R3m space group with unit cell parameters somewhat smaller than those of $\beta$-TCP, that is a $=0.7135 \mathrm{~nm}$ and $\mathrm{c}=2.5586 \mathrm{~nm}$.

Therefore, in spite of $\mathrm{G}_{\text {Si-Ca-P }}$ exhibiting a glassy matrix containing some crystalline domains like $\mathrm{G}_{\mathrm{Si}-\mathrm{Ca}}$, in the P-containing glass, the amorphous regions were depleted in calcium and exhibited shorter

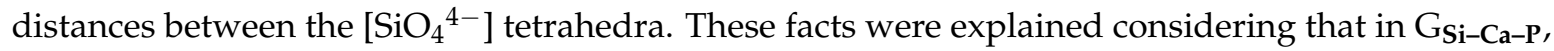
the $\mathrm{Ca}^{2+}$ ions were out of the glass network and bonded to phosphate in nanocrystals identified as Si-doped $\beta$-TCP with crystallites smaller than $10 \mathrm{~nm}$. Thus, HRTEM showed phase separation of silicate-rich (amorphous) and phosphate-rich (nanocrystalline) regions in the P-containing glass.

\subsection{Mechanism of Bioactivity of Bioactive Glasses Explained from Their Nanostructure}

The characterization of BG by HRTEM allowed the determination of the nanostructural factors relevant for the in vitro deposition of ACP and HCA. This characterization revealed that BGs exhibit short distance order features that greatly influence the glass dissolution and reactivity and, consequently, the formation of HCA in SBF. Moreover, HRTEM explained discrepancies in the kinetics of formation of HCA along the SBF tests (Figure 3). Calcium phosphate nanocystals in P-containing BG increased the silica network repolymerization, unfavorable for the initial glass reactivity. For this reason, the ACP formation was retarded in P-containing glasses (see Figure 3). However, these nanocrystals have the positive effect of behaving as nuclei, accelerating the HCA crystallization in the P-containing glasses. Therefore, the in vitro behavior of binary $\mathrm{G}_{\mathrm{Si}-\mathrm{Ca}}$ was conditioned by the location of the $\mathrm{Ca}^{2+}$ 
ions in an amorphous silica network, whereas in $\mathrm{G}_{\mathrm{Si}-\mathrm{Ca}-\mathrm{P}}$ they were present in silicon-doped calcium phosphate nanocrystals. This fact decreased the $\mathrm{Ca}^{2+}$ released to the medium when increasing the $\mathrm{P}_{2} \mathrm{O}_{5}$ content, which retarded ACP formation.

HRTEM explained the results from traditional characterization methods, for instance, the two very low-intensity bands at 604 and $567 \mathrm{~cm}^{-1}$ in the FTIR spectrum and the diffuse reflections at $26^{\circ}$ and $32^{\circ}$ in $2 \theta$ in the XRD pattern of $\mathrm{G}_{\text {Si-Ca-P }}$ before being soaked in SBF [18]. Both results suggested the presence of nanocrystalline phosphate nuclei in $\mathrm{G}_{\mathrm{Si}-\mathrm{Ca}-\mathrm{P}}$ that were visualized and identified by HRTEM. The $\mathrm{N}_{2}$ adsorption measurements also have shown that the additions of $\mathrm{P}_{2} \mathrm{O}_{5}$ produced the same effect of calcium decreasing the $\mathrm{CaO}$ content in $\mathrm{SiO}_{2}-\mathrm{CaO}$ glass. Again, HRTEM characterization also explained this fact because it showed the great affinity of phosphorus for calcium to form nanocrystals, consequently retaining the $\mathrm{Ca}^{2+}$ ions from the glass network.

\subsection{Recent Advances in the Characterization of the Nanostructure of Bioactive Glasses}

The pathway opened in 2005 by our group was followed by other authors. Thus, in 2007, Tilocca and Cormack confirmed by Molecular Dynamics simulations the structural effects of phosphorus inclusion in bioactive silicate glasses obtained by HRTEM. Their study was focused on the structural features that can have a role in the bioactive mechanism of dissolution and bone bonding [20]. They concluded that the higher affinity of $\mathrm{Na}^{+}$and $\mathrm{Ca}^{2+}$ cations for coordinating phosphate than of silicate and the $\mathrm{P}-\mathrm{O}-\mathrm{Si}$ linkages formation increased repolymerization of the silicate network with increasing $\mathrm{P}_{2} \mathrm{O}_{5}$. This negative effect of the $\mathrm{P}$ inclusion was counterbalanced by the concomitant increase for free orthophosphate groups, whose fast release is deemed to enhance the bioactivity. Thus, although the presence of $\mathrm{P}_{2} \mathrm{O}_{5}$ could reduce the glass bioactivity, the favorable balance between the effects mentioned should result in a positive effect of partial substitution of Si by P. Later on, Tilocca published a paper in 2009 reviewing advances in computer modelling of bioactive glasses based on MD simulations, which were starting to unveil key structural features of these materials [21].

Other groups, such as Aguiar et al. [22], investigated structural aspects of MPGs by HRTEM, FTIR, and ${ }^{29} \mathrm{Si}$ and ${ }^{31} \mathrm{P}$ MAS NMR in 2008 . They concluded that $\mathrm{P}$ was present in nanocrystals with interplanar distances in the range $0.21-0.26 \mathrm{~nm}$. These glasses developed a surface calcium phosphate-rich layer without detecting the presence of an intermediate silica-rich layer. They suggested that the phosphate nanoregions may act as nucleation sites for the calcium phosphate-rich layer. Later on, this group investigated the nanostructure of $\mathrm{SiO}_{2}-\mathrm{P}_{2} \mathrm{O}_{5}-\mathrm{CaO}$ S-GG [23]. The study showed how the incorporation of calcium into the glass promoted the appearance of $\mathrm{P}-\mathrm{O}$ Nonbonding Oxygen (NBO) groups and that the glass nanostructure was induced to form $\mathrm{Ca}$-rich orthophosphate units.

In 2013, the structures of binary $\mathrm{CaO}-\mathrm{SiO}_{2}$ and ternary $\mathrm{CaO}-\mathrm{P}_{2} \mathrm{O}_{5}-\mathrm{SiO}_{2} \mathrm{~S}-\mathrm{GG}$ by $\mathrm{MD}$ simulations, using the melt-quenched and sol-gel protocols, were investigated [24]. The combined effects of the silicate network connectivity and the tendency to form or not form non-homogeneous domains were correlated. The composition with an optimal $\mathrm{Ca} / \mathrm{P}$ ratio was synthesized and the in vitro tests confirmed the prediction by MD. Furthermore, in a recent paper, the advantages of using reactive MD models of S-GG were discussed [25].

The influence of the nanostructure in the bioactive response was also investigated for other families of silica-based biomaterials, like the $\mathrm{CaO}-\mathrm{SiO}_{2}-\mathrm{PDMS}$ hybrid sonoaerogels [26]. The aerogels showed analogous microstructural features to BG exhibiting amorphous $\mathrm{Ca}$-free areas where the $\mathrm{Si}-\mathrm{O}-\mathrm{Si}$ distances were $0.23 \mathrm{~nm}$. Besides, Ca-containing crystalline nanodomains, of pseudowollastonite, $\mathrm{CaSiO}_{3}$, were detected in the hybrid containing $20 \% \mathrm{CaO}$ and $20 \%$ PDMS, the only one of the investigated series that exhibited a bioactive response in SBF.

\subsection{Nanostructural Characterization of Bioactive Glasses by Nuclear Magnetic Resonance}

Solid state NMR is also playing an important role in the characterization of the nanostructure of BGs and the relationship with their behavior in SBF. Besides the structural characteristics of BGs, which will be explained in this section, NMR was used to identify the material formed on the 
glasses when immersed in SBF, which will be the subject of the following section. Next, outstanding advances on the nanostructure of different BGs where NMR spectroscopy played a fundamental role are presented.

In 2008, Leonova et al. [27] investigated for the first time the local structures of $\mathrm{CaO}-\mathrm{SiO}_{2}-\mathrm{P}_{2} \mathrm{O}_{5}$ MBGs with variable composition by ${ }^{1} \mathrm{H},{ }^{29} \mathrm{Si}$ and ${ }^{31} \mathrm{P}$ NMR. A biphasic structural model was established (see Figure 6, left). Such a model was valid with minimal differences for the MBG composition richer in Ca (35.2 atom-\%) and for the two compositions with lower contents in this element (19.1 and 9.5 atom- $\%)$. The authors highlighted that the pore wall leads to a high accessibility of Ca and $\mathrm{P}$ to body fluids and related this model to the experimentally demonstrated high bioactivity in SBF for these materials.

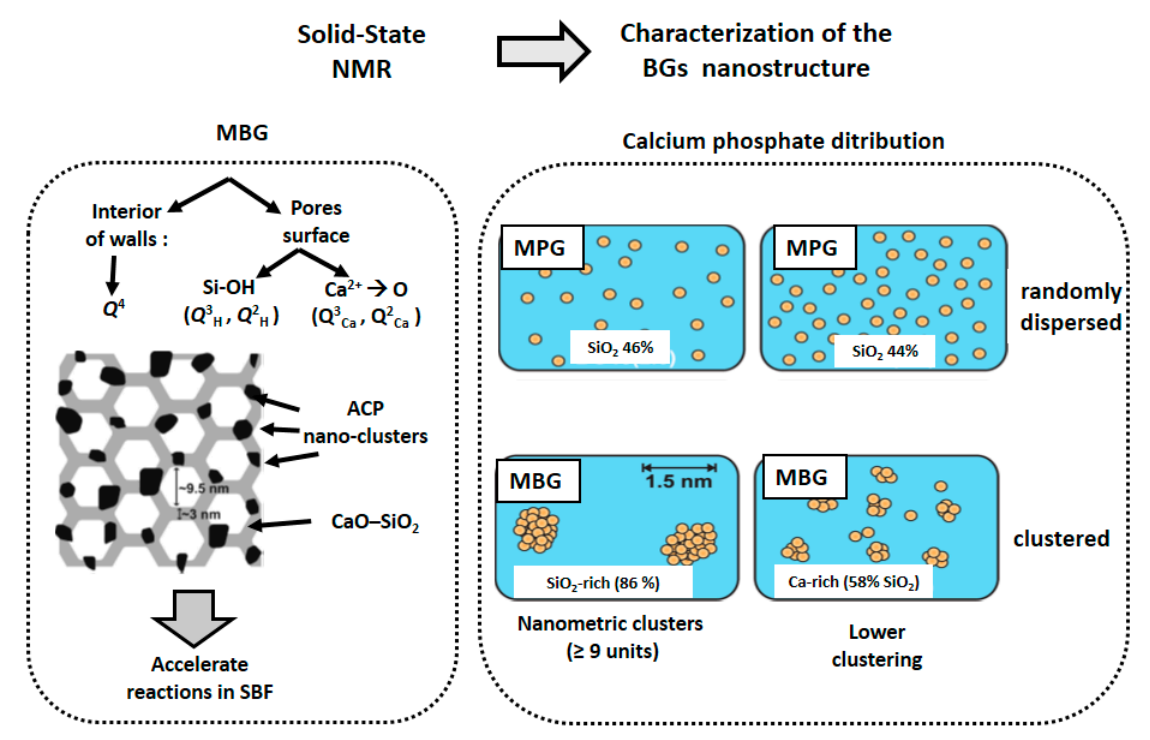

Figure 6. Solid state NMR allowed the determination of nanostructural features of BGs influencing the behavior in SBF. Left: The proposed model for MBGs contains ACP nanoclusters able to accelerate the reactivity in SBF. Right: NMR was also able to establish differences between MPGs and MBGs. In MPGs, phosphate ions are randomly dispersed, whereas in MBGs, nanometric clusters are formed whose size increases when the $\mathrm{SiO}_{2}$ in the glass increases.

Later on, in 2012, Gunawidjaja et al. [28] established a model showing the presence of phosphate nuclei on the MBG structure. They showed the advantages of using ${ }^{29} \mathrm{Si}$ and ${ }^{1} \mathrm{H}$ NMR spectroscopy for probing the local structures of bulk and surface portions of MBGs. ${ }^{29} \mathrm{Si}$ NMR spectra were obtained in conditions that allowed them to obtain quantitative information about the silicate speciation in the pore wall and at the MBG surface. The MBG surface was monitored after being in SBF for periods of time of up to 7 days. A depletion of $\mathrm{Ca}^{2+}$ ions at the MBG surface and a minor condensation of the silicate surface network over 7 days in SBF were observed. In 2013, this group probed the phosphate-ion distribution in some bioactive MPGs and MBGs by ${ }^{31} \mathrm{P}$ NMR [29]. The occurrence of transitions between random and clustered scenarios was evidenced (Figure 6, right). Phosphate species were randomly dispersed in Ca-rich MPGs $\left(\mathrm{SiO}_{2}\right.$ from 44 to 55 mol-\%), whereas Ca-poor MBG structures (86 $\mathrm{mol}-\% \mathrm{SiO}_{2}$ ) exhibited nanometric ACP clusters, comprising at least nine orthophosphate groups. In addition, a Ca-rich MBG (58 mol- $\% \mathrm{SiO}_{2}$ ) revealed a less pronounced phosphate clustering.

On the other hand, Fayon et al. [30] determined in 2013 the distribution and nature of nanometric-sized phosphate clusters in a bioactive MPG by ${ }^{31} \mathrm{P}$ NMR. It must be taken into account that dissolution of phosphates in MPGs raises the question of chemical homogeneity and the possible formation of clusters. Furthermore, the presence of phosphate clusters of 5 and $6\left[\mathrm{PO}_{4}\right]$ tetrahedral units embedded in the disordered polymeric silicate network was detected. In 2014, Svensson et al. [31] used simultaneously ${ }^{31} \mathrm{P}$ NMR and MD simulations to determine the phosphate distribution in eleven 
bioactive and non-bioactive phosphosilicate MPGs. They present an assessment of the distribution of phosphate groups across the structures, with the $\mathrm{P}$ content and silicate network connectivity varying independently.

\section{Characterization of HCA Formed In Vitro on Bioactive Glasses Mainly Using NMR}

NMR can also be used to analyze the HCA formed in SBF, allowing the identification of the formation steps of the calcium phosphate layer on BGs. Thus, in 2012, Gunawidjaja et al. [32] compared the biomimetic growth of HA from a MBG in SBF and buffered water by solid state NMR, powder XRD, SEM, and EDX. The effect of using two MBG concentrations was examined. The relative amounts of ACP and HA were quantified by XRD and ${ }^{31} \mathrm{P}$. For high MBG loadings, the HA formation reduced in SBF compared to buffered water. These features stem from a high $\left[\mathrm{Ca}^{2+}\right] /\left[\mathrm{PO}_{3}{ }^{4-}\right]$ ratio resulting in the medium, which retards the HA crystallization by inducing a rapid ACP precipitation.

In 2015, the composition-dependent in vitro formation of apatite at MBG surfaces was quantified by ${ }^{31} \mathrm{P}$ NMR and XRD [33]. That way, the first quantitative assessment of the HCA growth in SBF from a BG was reported (Figure 7, top). The authors determined a profile of the relative ACP/HCA fractions layer formed at each MBG and assay time. The HCA in each BG after the SBF treatment and the composition of Ca-depleted MBG phase were determined from XRD in conjunction with measured concentrations of $\mathrm{Ca}, \mathrm{Si}$, and $\mathrm{P}$ in solution. The HCA formation observed increased concurrently with the $\mathrm{Ca}$ and $\mathrm{P}$ contents of the MBG. The results of this study highlight the importance of adapting the concentration of the biomaterial to its composition to avoid perturbing the HCA crystallization, altering the outcome of the SBF assays.

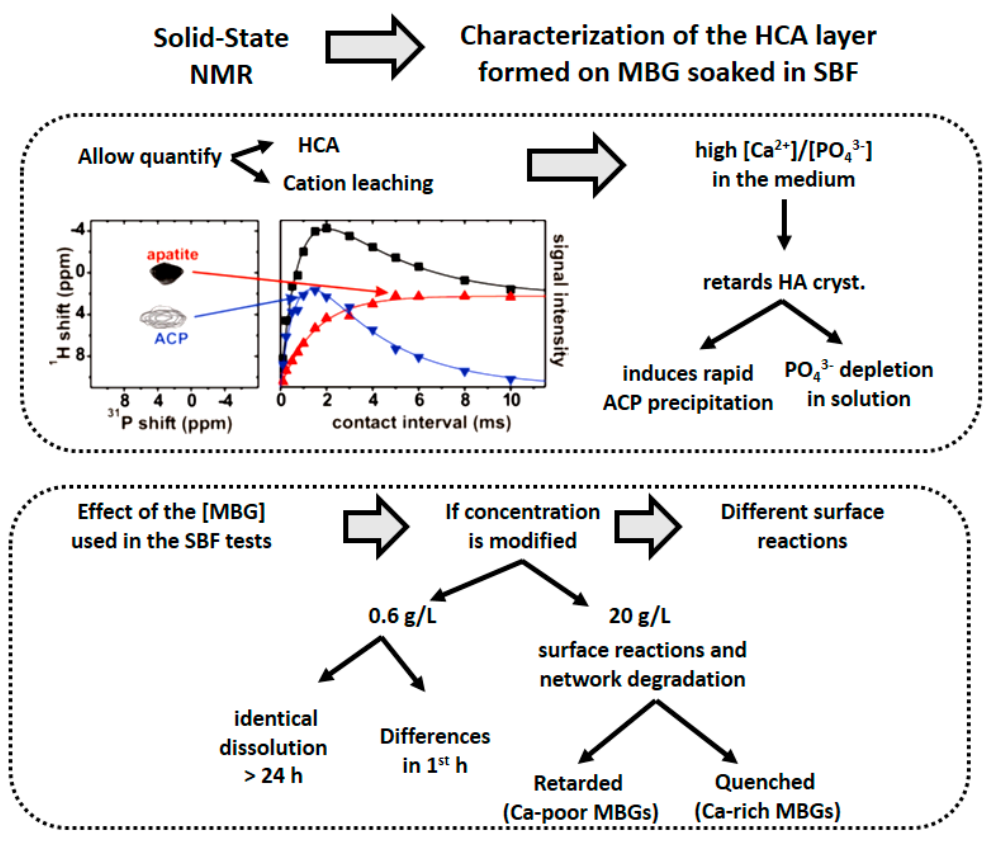

Figure 7. NMR can be used to characterize the HCA coating the bioactive MBG after being soaked in SBF. Top: The relative amount of ACP and HCA in the newly formed layer was quantified. NMR demonstrated that high $\mathrm{Ca}^{2+} / \mathrm{PO}_{4}{ }^{3-}$ ratios in the surrounding liquid medium retarded the HCA formation on MBG. Bottom: NMR demonstrated the effect of the MBG concentration used in the SBF tests.

In 2016, the surface reactions of MBGs monitored by ${ }^{29} \mathrm{Si}$ NMR and the effects of particles of glass concentration in SBF were reported (Figure 7, bottom) [34]. MBG revealed different surface alterations between low $(0.6 \mathrm{~g} / \mathrm{L})$ and high $(20 \mathrm{~g} / \mathrm{L}) \mathrm{MBG}$ concentrations in SBF. For the low MBG dose, expected to be more relevant for in vivo conditions, all MBGs followed a similar dissolution 
mechanism beyond $24 \mathrm{~h}$. In contrast, for high MBG concentrations, the surface reactions and their associated silicate network degradation were retarded for Ca-poor MBGs, whereas the reactions were completely quenched for Ca-rich compositions. These findings simplify future MBG design by identifying the compositional and textural factors relevant for a rapid in vitro formation of HCA.

In 2017, Mathew et al. monitored the proton environments in calcium phosphates formed in vitro from MBGs by ${ }^{1} \mathrm{H}$ NMR [35]. The evolution of the proton speciation was elucidated at the MBG surface and within each $\mathrm{ACP} / \mathrm{HCA}$ constituent of the layer formed after immersed in SBF. The initially prevailing $\mathrm{ACP}$ phase comprises $\mathrm{H}_{2} \mathrm{O} \mathrm{HPO}_{4}{ }^{2-} / \mathrm{PO}_{4}{ }^{3-}$ groups in a non-apatite structure. When the soaking time increased, a transformation of ACP to HCA was evidenced. They demonstrated that ${ }^{1} \mathrm{H}^{31} \mathrm{P}$ cross-polarization NMR was more sensitive than powder XRD or ${ }^{31} \mathrm{P}$ NMR for detecting the onset of HCA formation, mainly for P-containing MBGs.

\section{Future Perspectives and Conclusions}

Determining the structure of glasses on the nanoscale is essential to understand why some glasses are coated with an HCA layer when soaked in fluids that simulate human plasma. Furthermore, it is necessary to understand the different bioactivity mechanisms observed, as a function of the presence or absence of phosphorus in the glasses' composition.

After the first paper describing the nanostructure of two BGs [15], many research groups investigated the glasses' characterization on the atomic scale by experimental techniques including HRTEM, MD, and NMR. The final aim was to establish relationships between the glasses' nanostructure and the bioactive behavior. These studies, extended to the three families of bioactive glasses, i.e., MPGs, S-GGs, and MBGs, allowed the elucidation of unknown aspects of the apatite layer formation under in vitro conditions. In P-containing BGs, the nanostructural characterization revealed that $\mathrm{Ca}^{2+}$ ions are out of the glass network and bonded to phosphorus, forming silicon-doped calcium phosphate nanocrystals. This fact explains the different mechanisms of formation of the apatite layer depending on the presence or absence of $\mathrm{P}$ in the glass.

Figure 8 summarizes the properties of glasses influencing the in vitro behavior in SBF. Besides composition, method of synthesis, and textural properties (for S-GGs and MBGs), the nanostructural characterization plays an important role in the design of new BGs for tissue engineering because it allows the prediction of its behavior in the human body when implanted.

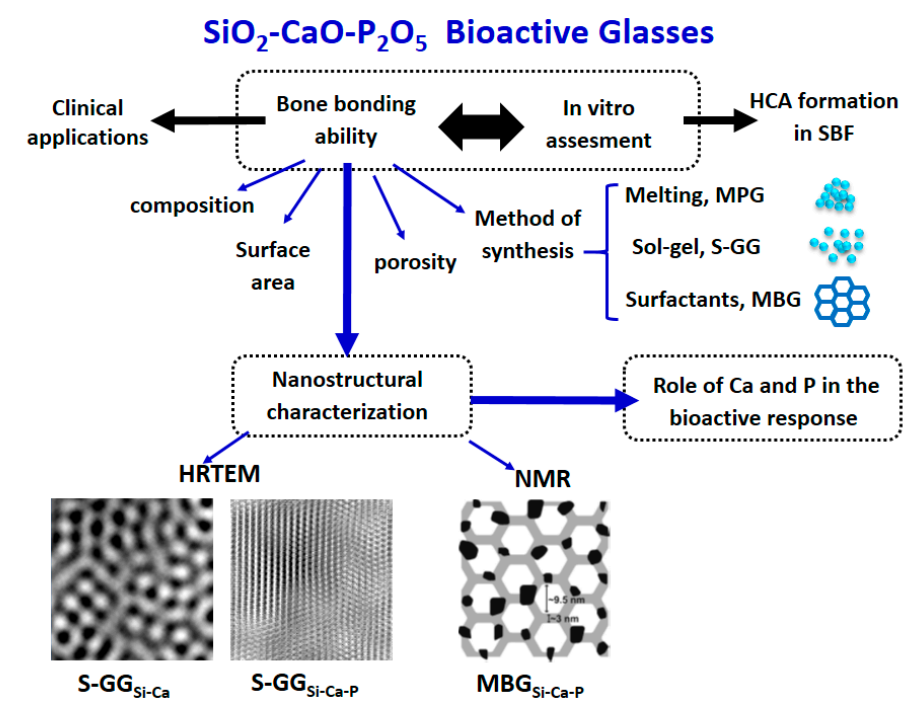

Figure 8. The nanostrucural characterization of glasses allows the explanation of the different mechanisms of formation of the HCA layer after being soaked in SBF. The relationship of composition and textural properties with the in vitro bioactive response was profusely investigated, but the nanostructural features of the BGs also exert a critical role in the glasses' reactivity. 
Acknowledgments: The authors deny any conflicts of interest. This study was supported by research grants from the European Research Council, ERC-2015-AdG, Advanced Grant Verdi-Proposal No.694160, MINECO MAT2015-64831-R project and Instituto de Salud Carlos III, PI15/00978, project co-financed with the European Union FEDER funds.

Author Contributions: María Vallet-Regí and Antonio J. Salinas conceived, designed and write this review paper. Conflicts of Interest: The authors declare no conflict of interest.

\section{References}

1. Hench, L.L. Bioglass: 10 milestones from concept to commerce. J. Non-Cryst. Solids 2016, 432, 2-8. [CrossRef]

2. Vallet-Regí, M.; Salinas, A.J. Mesoporous Bioactive Glasses in Tissue Engineering and Drug Delivery. In Bioactive Glasses: Fundamentals, Technology and Applications; Boccaccini, A.R., Brauer, D.S., Hupa, L., Eds.; The Royal Society of Chemistry: London, UK, 2017; pp. 393-419.

3. Salinas, A.J.; Vallet-Regí, N. Glasses in bone regeneration: A multiscale issue. J. Non-Cryst. Solids 2016, 432, 9-14. [CrossRef]

4. Jones, J.R. Review of bioactive glass: From Hench to hybrids. Acta Biomater. 2013, 9, 4457-4486. [CrossRef] [PubMed]

5. Hoppe, A.; Güldal, N.S.; Boccaccini, A.R. A review of the biological response to ionic dissolution products from bioactive glasses and glass-ceramics. Biomaterials 2011, 32, 2757-2774. [CrossRef] [PubMed]

6. Lindfors, N.C.; Koski, I.; Heikkilä, J.T.; Mattila, K.; Aho, A.J. A prospective randomized 14-year follow-up study of bioactive glass and autogenous bone as bone graft substitutes in benign bone tumors. J. Biomed. Mater. Res. B Appl. Biomater. 2010, 4, 157-164. [CrossRef] [PubMed]

7. Vallet-Regí, M.; Ragel, C.V.; Salinas, A.J. Glasses with medical applications. Eur. J. Inorg. Chem. 2003, 1029-1042. [CrossRef]

8. Hench, L.L.; Splinter, R.J.; Allen, W.C.; Greenlee, T.K. Bonding mechanisms at the interface of ceramic prosthetic materials. J. Biomed. Mater. Res. 1971, 2, 117-141. [CrossRef]

9. Li, R.; Clark, A.E.; Hench, L.L. An investigation of bioactive glass powders by sol-gel processing. J. Appl. Biomater. 1991, 2, 231-239. [CrossRef] [PubMed]

10. Yan, X.; Yu, C.; Zhou, X.; Tang, J.; Zhao, D. Highly ordered mesoporous bioactive glasses with superior in vitro bone forming bioactivities. Angew. Chem. Int. Ed. 2004, 43, 5980-5984. [CrossRef] [PubMed]

11. Izquierdo-Barba, I.; Salinas, A.J.; Vallet-Regí, M. Effect of the continuous solution exchange on the in vitro reactivity of a CaO-SiO 2 sol-gel glass. J. Biomed. Mater. Res. A 2000, 51, 191-199. [CrossRef]

12. Kokubo, T.; Takadama, H. How useful is SBF in predicting in vivo bone bioactivity? Biomaterials 2006, 27, 2907-2915. [CrossRef] [PubMed]

13. Maçon, A.L.B.; Kim, T.B.; Valliant, E.M.; Goetschius, K.; Brow, R.K.; Day, D.E.; Hoppe, A.; Boccaccini, A.R.; Kim, I.Y.; Ohtsuki, C.; et al. A unified in vitro evaluation for apatite-forming ability of bioactive glasses and their variants. J. Mater. Sci. Mater. Med. 2015, 26, 115. [CrossRef] [PubMed]

14. Zadpoor, A.A. Relationship between in vitro apatite-forming ability measured using simulated body fluid and in vivo bioactivity of biomaterials. Mater. Sci. Eng. C Mater. Biol. Appl. 2014, 35, 134-143. [CrossRef] [PubMed]

15. Vallet-Regí, M.; Salinas, A.J.; Ramírez-Castellanos, J.; González-Calbet, J.M. Nanostructure of bioactive sol-gel glasses and organic-inorganic hybrids. Chem. Mater. 2005, 17, 1874-1879. [CrossRef]

16. Vallet-Regí, M.; Izquierdo-Barba, I.; Salinas, A.J. Influence of $\mathrm{P}_{2} \mathrm{O}_{5}$ on crystallinity of apatite formed in vitro on surface of bioactive glass. J. Biomed. Mater. Res. 1999, 46, 560-565. [CrossRef]

17. Salinas, A.J.; Vallet-Regí, M.; Izquierdo-Barba, I. Biomimetic apatite deposition on calcium silicate gel glasses. J. Sol-Gel Sci. Technol. 2001, 21, 13-25. [CrossRef]

18. Salinas, A.J.; Martin, A.I.; Vallet-Regí, M. Bioactivity of three $\mathrm{CaO}-\mathrm{P}_{2} \mathrm{O}_{5}-\mathrm{SiO}_{2}$ sol-gel glasses. J. Biomed. Mater. Res. 2002, 61, 524-532. [CrossRef] [PubMed]

19. Dickens, B.; Schroeder, L.W.; Brown, W.E. Crystallographic studies of the role of $\mathrm{Mg}$ as a stabilizing impurity in beta-Ca $\left(\mathrm{PO}_{4}\right)_{2}$. I. The crystal structure of pure beta-Ca $\left(\mathrm{PO}_{4}\right)_{2}$. J. Solid State Chem. 1974, 10, 232-248. [CrossRef]

20. Tilocca, A.; Cormack, A.N. Structural effects of phosphorus inclusion in bioactive silicate glasses. J. Phys. Chem. B 2007, 111, 14256-14264. [CrossRef] [PubMed] 
21. Tilocca, A. Structural models of bioactive glasses from molecular dynamics simulations, Proc. R. Soc. A 2009, 465, 1003-1027. [CrossRef]

22. Aguiar, H.; Solla, E.L.; Serra, J.; Gonzalez, P.; Leon, B.; Almeida, N.; Cachinho, S.; Davim, E.J.C.; Correia, R.; Oliveira, J.M.; et al. Orthophosphate nanostructures in $\mathrm{SiO}_{2}-\mathrm{P}_{2} \mathrm{O}_{5}-\mathrm{CaO}-\mathrm{Na}{ }_{2} \mathrm{O}-\mathrm{MgO}$ bioactive glasses. J. Non-Cryst. Solids 2008, 354, 4075-4080. [CrossRef]

23. Aguiar, H.; Serra, J.; Gonzalez, P. Nanostructural Transitions in Bioactive Sol-Gel Silicate Glasses. Int. J. Appl. Ceram. Technol. 2011, 8, 511-522. [CrossRef]

24. Malavasi, G.; Menabue, L.; Menziani, M.C.; Pedone, A.; Salinas, A.J.; Vallet-Regí, M. New insights into the bioactivity of $\mathrm{SiO}_{2}-\mathrm{CaO}$ and $\mathrm{SiO}_{2}-\mathrm{CaO}-\mathrm{P}_{2} \mathrm{O}_{5}$ sol-gel glasses by molecular dynamics simulations. J. Sol-Gel Sci. Technol. 2013, 67, 208-219. [CrossRef]

25. Cote, A.S.; Cormack, A.N.; Tilocca, A. Reactive molecular dynamics: An effective tool for modelling the sol-gel synthesis of bioglasses. J. Mater. Sci. 2017, 52, 9006-9013. [CrossRef]

26. Salinas, A.J.; Vallet-Regí, M.; Toledo-Fernandez, J.A.; Mendoza-Serna, R.; Pinero, M.; Esquivias, L.; Ramirez-Castellanos, J.; Gonzalez-Calbet, J.M. Nanostructure and Bioactivity of Hybrid Aerogels. Chem. Mater. 2009, 21, 41-47. [CrossRef]

27. Leonova, E.; Izquierdo-Barba, I.; Arcos, D.; Lopez-Noriega, A.; Hedin, N.; Vallet-Regì, M.; Edén, M. Multinuclear solid state NMR studies of ordered mesoporous bioactive glasses J. Phys. Chem. C 2008, 112, 5552-5562. [CrossRef]

28. Gunawidjaja, P.N.; Mathew, R.; Lo, A.Y.H.; Izquierdo-Barba, I.; Garcia, A.; Arcos, D.; Vallet-Regì, M.; Edén, M. Local structures of mesoporous bioactive glasses and their surface alterations in vitro: Inferences from solid-state nuclear magnetic resonance. Philos. Trans. R. Soc. A 2012, 370, 1376-1399. [CrossRef] [PubMed]

29. Mathew, R.; Turdean-Ionescu, C.; Stevensson, B.; Izquierdo-Barba, I.; Garcia, A.; Arcos, D.; Vallet-Regí, M.; Edén, M. Direct Probing of the Phosphate-Ion Distribution in Bioactive Silicate Glasses by Solid-State NMR: Evidence for Transitions between Random/Clustered Scenarios Chem. Mater. 2013, 25, 1877-1885. [CrossRef]

30. Fayon, F.; Dueem, C.; Poumeyrol, T.; Allix, M.; Massiot, D. Evidence of Nanometric-Sized Phosphate Clusters in Bioactive Glasses as Revealed by Solid-State P-31 NMR. J. Phys. Chem. C 2013, 117, 2283-2288. [CrossRef]

31. Stevensson, B.; Mathew, R.; Edén, M. Assessing the Phosphate Distribution in Bioactive Phosphosilicate Glasses by P-31 Solid-State NMR and Molecular Dynamics Simulations J. Phys. Chem. B 2014, 118, 8863-8876. [CrossRef] [PubMed]

32. Gunawidjaja, P.N.; Izquierdo-Barba, I.; Mathew, R.; Jansson, K.; García, A.; Grins, J.; Arcos, D.; Vallet-Regí, M.; Edén, M. Quantifying apatite formation and cation leaching from mesoporous bioactive glasses in vitro: A SEM, solid-state NMR and powder XRD study. J. Mater. Chem. 2012, 22, 7214-7223. [CrossRef]

33. Turdean-Ionescu, C.; Stevensson, B.; Grins, J.; Izquierdo-Barba, I.; García, A.; Arcos, D.; Vallet-Regí, M.; Edén, M. Composition-dependent in vitro apatite formation at mesoporous bioactive glass-surfaces quantified by solid-state NMR and powder XRD. RSC Adv. 2015, 5, 86061-86071. [CrossRef]

34. Turean-Ionescu, C.; Stevensson, B.; Izquierdo-Barba, I.; García, A.; Arcos, D.; Vallet-Regì, M.; Edén, M. Surface Reactions of Mesoporous Bioactive Glasses Monitored by Solid-State NMR: Concentration Effects in Simulated Body Fluid. J. Phys. Chem. C 2016, 120, 4961-4974. [CrossRef]

35. Mathew, R.; Turdean-Ionescu, C.; Yu, Y.; Stevensson, B.; Izquierdo-Barba, I.; García, A.; Arcos, D.; Vallet-Regì, M.; Edén, M. Proton Environments in Biomimetic Calcium Phosphates Formed from Mesoporous Bioactive $\mathrm{CaO}-\mathrm{SiO}_{2}-\mathrm{P}_{2} \mathrm{O}_{5}$ Glasses in Vitro: Insights from Solid-State NMR. J. Phys. Chem. C 2017, 121, 13223-13238. [CrossRef] [PubMed]

(C) 2018 by the authors. Licensee MDPI, Basel, Switzerland. This article is an open access article distributed under the terms and conditions of the Creative Commons Attribution (CC BY) license (http:/ / creativecommons.org/licenses/by/4.0/). 